\begin{tabular}{|l|llll|}
\hline & \multicolumn{4}{|c|}{ PORT-SAID ENGINEERING RESEARCH JOURNAL } \\
Faculty of Engineering - Port Said University & \\
\hline
\end{tabular}

\title{
Rational Design of Inland Water Vessels
}

\author{
M.A.Shamah ${ }^{1}$, Y.A.Abdel-Nasser ${ }^{2}$ and M.M.Abdel-Rahim ${ }^{3}$
}

\begin{abstract}
This paper has demonstrated the design aspects for inland water units working in the River Nile. The acting loads and stresses induced in the structural elements of inland units are still water bending moment and stresses, local hydrostatic pressure and local stresses. A rational structural analysis procedure is developed and applied. This approach will result in decreasing the lightweight. Accordingly, this weight will increase the cargo capacity in the inland water units which will economically affect all terms of the transportation business.
\end{abstract}

Keywords: Nile barges, Rational design, strength estimation, modes of failure

\section{Abbreviations}

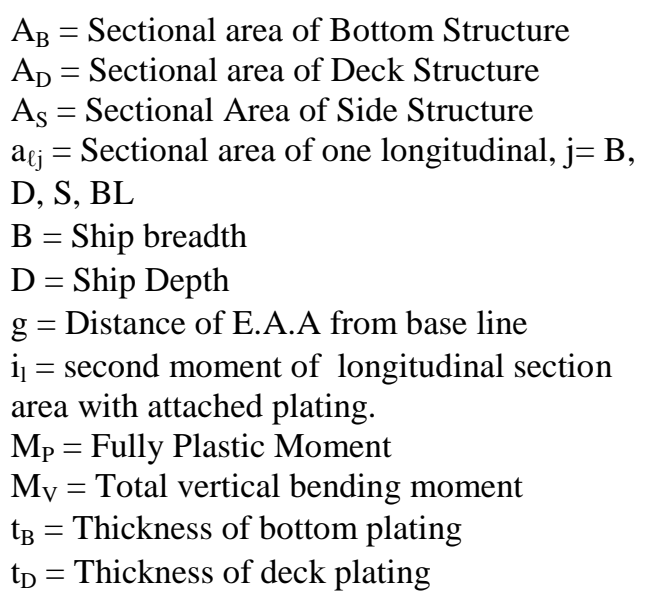

\section{Introduction}

Regarding inland navigation vessels various design aspects should be taken into account such as cargo capacity, speed and environment. The design aspects which will be considered as a priority vary from one place to another according to various considerations. In Bangladesh, some recommendations were proposed by optimizing the hull shape of some existing vessels to reduce the effects of $\mathrm{CO}_{2}$ emission [1]. Another research work was studied flow around an inland waterway vessel in shallow water CFD model.

\footnotetext{
1, 2 Professor, Department of Naval Architecture and Marine Engineering, Faculty of Engineering, Alexandria University

${ }^{3}$ M.Sc. Student, Department of Naval Architecture and Marine Engineering, Faculty of Engineering, Alexandria University, mohanad832@gmail.com
}

$$
\begin{aligned}
& t_{s}=\text { Thickness of side shell plating } \\
& t_{B L}=\text { Thickness of longitudinal bulkhead } \\
& \text { plating } \\
& y_{p}=\text { distance of the attached plating from the } \\
& \text { neutral axis of the longitudinal section. } \\
& Z_{\mathrm{eB}}=\text { elastic modulus of ship section at } \\
& \text { bottom } \\
& Z_{\mathrm{eD}}=\text { elastic modulus of ship section at deck } \\
& \mathrm{Z}_{\mathrm{P}}=\text { Plastic Section Modulus } \\
& \sigma_{\mathrm{cr}}=\text { critical buckling stress of deck plating } \\
& \sigma_{\mathrm{B}}=\text { Hull girder stress at bottom plating due } \\
& \text { to }\left(\mathrm{M}_{\mathrm{V}}\right) \\
& \sigma_{\mathrm{y}}=\text { Yield strength of the material }
\end{aligned}
$$

Theoretical data were compared to the results of towing tank measurements to comprise ship resistance, wave profile on hull surface, and distribution of velocity in flow around bow and stern [2]. In Poland a research was made about the future of inland water transport regarding the diesel fuel consumption by inland waterway. It was found that inland water transportation has a lower saving in fuel consumption for the same amount of cargo than that used for other modes of transportations. The expected total sum of inland water transportation by 2027 will be 2.57 million TEU per year [3].

The term basic design refers to the determination of major ship characteristics affecting cost and performance. Basic design includes the selection of ship dimensions, hull form, power, preliminary arrangement of hull and machinery, and major structure. Proper selections assure the attainment of the mission requirements such as good seakeeping performance, maneuverability, the desired speed, endurance, cargo capacity, and deadweight [4]. The 
procedures of design are illustrated in the Design Spiral, Evans (1959). (See Fig.1)

In this paper, a redesign of the inland water units on the basis of the rational structural analysis is applied. The rational structural analysis includes the elastic and plastic stresses analyses of a unit. It composed from different stages of analyses such as primary, secondary and tertiary analysis in addition to the plastic analysis. Applied this approach on an existing inland water unit will lead to decrease the building materials that required for this unit.

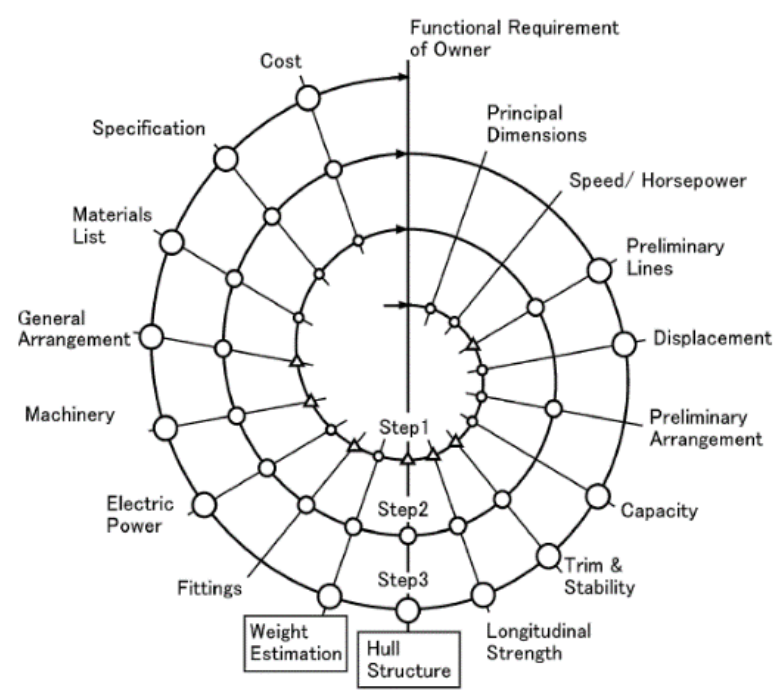

Fig.1 Design spiral [4]

\section{Structural analysis for inland water units}

The hull structure has been planned originally by the designer in a way that the structure can effectively resist the presumed maximum load which is estimated from previous experience of failure modes. Therefore, once damage occurs in the structure, it indicates the following facts:

- The magnitude of the load causing the failure is greater than or equals the expected load.

- The actual failure takes place in a different mode from the presumed one.

\subsection{Procedures of ship design}

The following design procedures are adopted in order to consider the structural strength estimation:

- Determine an initial stiffening system of structural members.
- Presume a magnitude, direction and probability of load.

- Assume failure mode of structure due to the load.

\section{Modes of failure}

There are several failure modes experienced in inland water units [4]. The following modes are significant when dealt with the structural analysis:

- $\quad$ Yielding

- Buckling

- Fatigue

- material deterioration due to corrosion

\subsection{Yielding of structural members}

When the load applied to a certain structure exceeds a certain critical value, the elongation would increase rapidly. This elongation is called yielding. The designer usually takes care to maintain the strength of the structure so as not to exceed the yielding point.

\subsection{Buckling of structural members}

If a structure is subjected to a compressive load, it may suddenly deflect once the load reaches a critical value. This critical value is called buckling point. When a large deflection takes place, the structure may not recover its original shape even when the load is removed.

\subsection{Fatigue}

The structure may be fractured by small loads when they are repeated regularly .The fracture happens because of fatigue. Fatigue may occur from lower loads than yielding strength, especially where the number of cycles is very large. That type of fracture is sometimes caused by vibration, especially if the frequency is very high. Fatigue doesn't have a great effect in the case of Rive Nile units because there are no waves, therefore the structure is subjected only to cyclic loads resulted from the machinery which could be neglected in that case .

\subsection{Material deterioration due to corrosion}

It is a natural process which converts a refined metal to a more chemically-stable form. It is the gradual destruction of material by electrochemical reaction with their environment such as sea water. This must be considered as a mode of failure.

Deterioration is not expected to be severe for inland water units because the vessel is working in fresh water. 


\section{Stresses induced in ship structural members}

All strength members of ship structures are subjected to several types of stresses induced by external and internal loads. The fabrication of ship structural members by gas cutting, forming, welding and assembly work induce complicated systems of residual stresses. These residual stresses do not appear in the structural members as they are in internal equilibrium. The hull girder of a ship is subjected to longitudinal vertical and horizontal bending moments, shear forces and torsional moments. These hull girder loadings induce stresses referred to as primary stresses in the primary strength members. Strength members of ship structure assemblies are subjected to cargo and external water pressure loadings which induce stresses called secondary stresses. Tertiary strength members are subjected to tertiary loadings which induce a third type of stresses called tertiary stresses. The bottom plating is subjected to additional local loadings exerted by the external hydrostatic water pressure. These local loadings cause bending of bottom plate panels and thus induce local bending stresses [5]. (See Fig. 3)

The compounding of these stresses for some strength members could reach unacceptable high values of equivalent stresses which may exceed the allowed stresses of the material and cause structural failure.

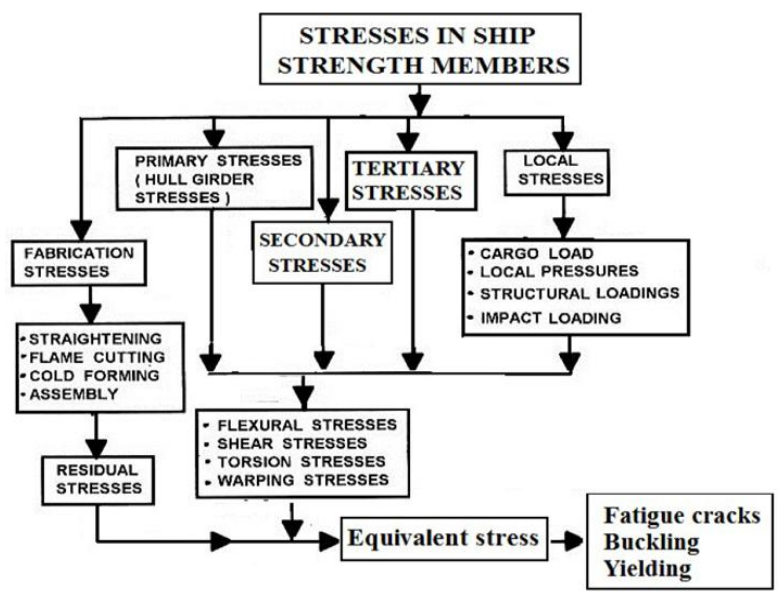

Fig.2 Various stresses affecting ship structure [5]

\subsection{Hull Girder Bending Stress Components}

The hull girder primary stresses are induced by the following bending moment components:

1) Stresses due to longitudinal vertical bending moments:

1. Still water bending stresses

2. Wave-induced bending stresses (sagging /hogging conditions)

3. Dynamic stresses

2) Stresses due to horizontal bending moment.
Wave-induced bending stresses, dynamic stresses and stresses due to horizontal bending moment don't affect the structure in the case of River Nile units, because there are no waves in the River Nile.

Still water bending stress is the only stress that can be taken into consideration in this case.

\subsubsection{Hull Girder Primary Stresses Induced by Longitudinal Vertical Bending Moments}

The hull girder primary stresses at the deck and bottom plating due to a longitudinal vertical bending moment [5].(see Fig.3)

$\sigma_{\mathrm{B}}=\frac{M_{V}}{z_{e B}}$

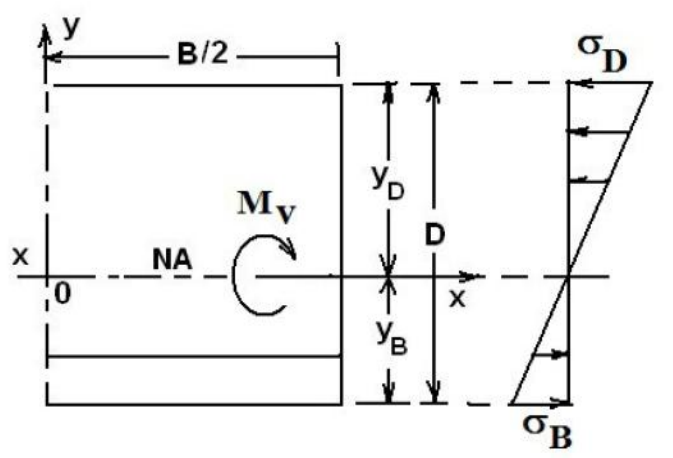

Fig.3 Primary stresses induced by bending moment [5]

\subsubsection{Secondary Stresses in structural members}

The secondary stresses are induced by the secondary moments and shear forces. These loadings could be determined by analyzing a specified length of the secondary structure assembly such as a hold length. This structure assembly comprises a full hold length plus half hold length aft and forward of the selected hold. An example is given for the case when the full hold length is fully loaded and the two half hold lengths are empty. (See Fig.5)

Secondary stresses don't exist in this case because most of the inland water units have only two cargo holds. It is illogical to fill one hold with cargo and leave the other hold empty.

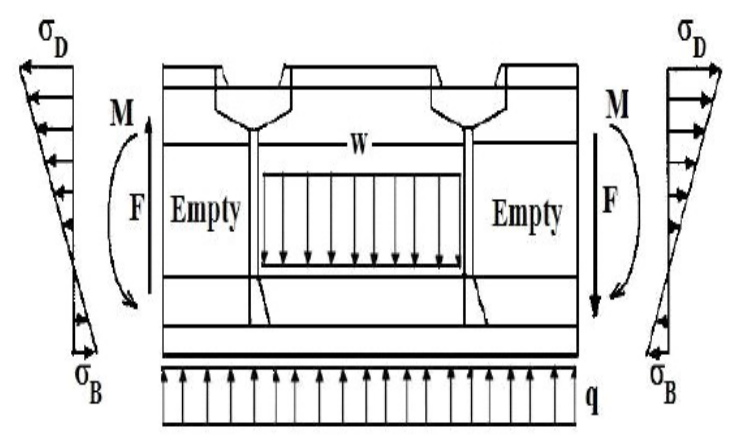

Fig.4 Secondary stresses [5]

\subsubsection{Tertiary Loading and Stresses in structural members}


In bottom structures, the strength members sustaining the tertiary stresses are the bottom and tank top longitudinals and plating. The following are examples of tertiary stresses of analyses.

Each bottom longitudinal is subject to a load which is spread over a rectangular area of length "a" equal to the longitudinal length between two floors, and breadth "b" equal to the sum of the half-spaces between two adjacent longitudinals or between a longitudinal and the adjacent girder. Bottom longitudinals are also subjected to in-plane normal loadings exerted on the longitudinal cross section. (See Fig.5) These normal tensile or compressive stresses are induced by hull girder and secondary bending moments [5].

The bending stress at the attached bottom plating is given by:

$$
\sigma_{\mathrm{P}}=\frac{m y_{p}}{i_{I}}
$$
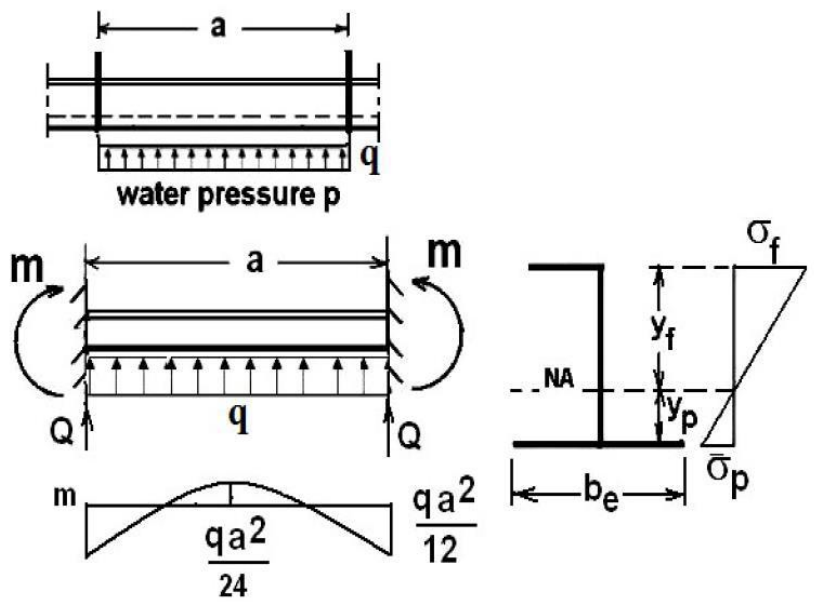

Fig.5 Tertiary stresses affecting bottom plate [5]

The hydrostatic pressure exerted on the outer shell plating represents the main local loading on bottom longitudinals. The design loads are expressed in terms of bending moments and shear forces and can be calculated by the simple beam theory. (See Fig.6)

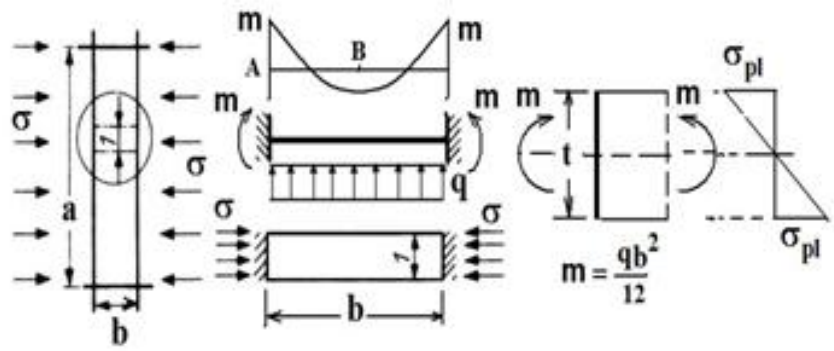

Fig.6 Local bending stress in bottom plating in the transverse direction [5]

\subsection{Compounding of Stresses in Ship Strength Members.}

The most common process of calculating the strength of ship structure is based on the calculation of both longitudinal and local stresses. The stresses affecting each ship structural member should be estimated according to the compounded stresses imposed on them by the longitudinal bending action of the ship hull girder and the induced bending under the local loads. (See Fig.7)

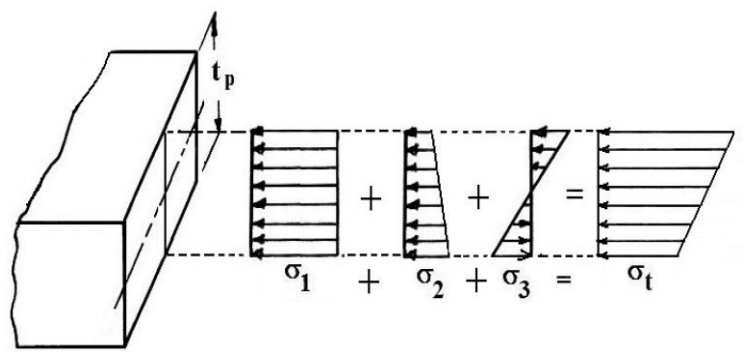

Fig.7 Compounding of stresses on bottom plating

\section{Plastic structural analysis of inland water units}

In the plastic design method of a structure, the whole structure is affected by the yield stress. The plastic stress has occurred due to the fact that the ultimate load is found from the strength of steel in the plastic range [6]. The strength of steel beyond the yield stress is fully utilized in this method. It provides striking economy regarding the weight of steel since the sections designed by this method are smaller in size than those designed by the elastic design method.

\subsection{Calculation of plastic bending moment}

In reality the exact analysis of a structure can never be carried out. Idealizing a structure is a method of conservatively simplifying the components of the structural system, while keeping the same behavior under loading the same. This is done in order to simplify calculations. Without an idealized structure, design could take a massively longer time.

The Neutral axis (NA) is associated with the fiber that does not undergo change in its length when an element bends and stresses are all less than yield stress. Equal area axis (EAA) is the location of the axis which results in equal compressive and tensile forces when all fibers in a section have reached yield stress. (See Fig.8)

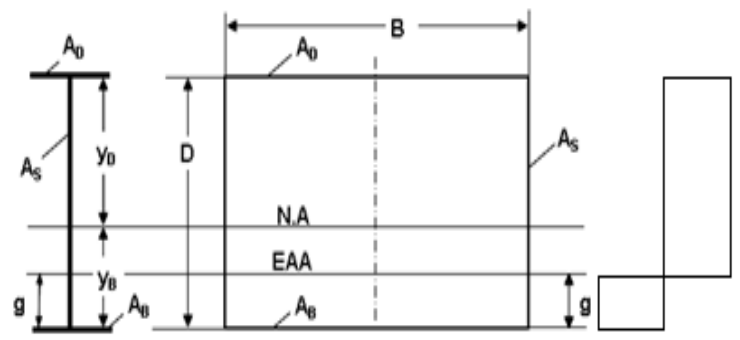

Fig. 8 Midship section 
The plastic section modulus for the ship section is given by:

$$
Z_{P}=A_{D} \cdot g+2 A_{s}\left(\frac{D}{2}-g+\frac{g^{2}}{D}\right)+A_{B}(D-g)
$$

The distance between equal area axis and the base line in given by:

$$
\begin{aligned}
& \mathrm{g}=\mathrm{D}\left[\frac{\mathrm{A}_{\mathrm{B}}+2 \mathrm{~A}_{\mathrm{g}}-\mathrm{A}_{\mathrm{D}}}{4 \mathrm{~A}_{\mathrm{g}}}\right] \\
& \mathrm{A}_{\mathrm{B}}=\mathrm{B} \cdot \mathrm{t}_{\mathrm{B}}+\sum \mathrm{a}_{\mathrm{fb}} \\
& \mathrm{A}_{\mathrm{D}}=\mathrm{B} \cdot \mathrm{t}_{\mathrm{D}}+\sum \mathrm{a}_{\mathrm{gD}} \\
& \mathrm{A}_{\mathrm{S}}=\mathrm{D} \cdot\left(\mathrm{t}_{\mathrm{s}}+\mathrm{t}_{\mathrm{BL}}\right)+\sum\left(\mathrm{a}_{\mathrm{gs}}+\mathrm{a}_{\mathrm{gBL}}\right)
\end{aligned}
$$

The plastic moment $\mathrm{M}_{\mathrm{p}}$ is given by:

$$
\mathrm{M}_{\mathrm{P}}=\mathrm{Z}_{\mathrm{p}} \cdot \sigma_{\mathrm{Y}}
$$

\section{Case study}

Our case study is a self-propelled Nile barge, which was constructed in 2015.

The following particulars are as follows:

- $\quad \mathrm{LBP}=67.735 \mathrm{~m}$

- $\mathrm{LOA}=70 \mathrm{~m}$

- $\mathrm{LWL}=68.985 \mathrm{~m}$

- $\quad$ Breadth $=10 \mathrm{~m}$

- Depth $=2.8 \mathrm{~m}$

- $\quad$ Draft $=1.8 \mathrm{~m}$

- $\quad \mathrm{CB}=0.899$

- $\quad$ Light weight $=323.6$ ton

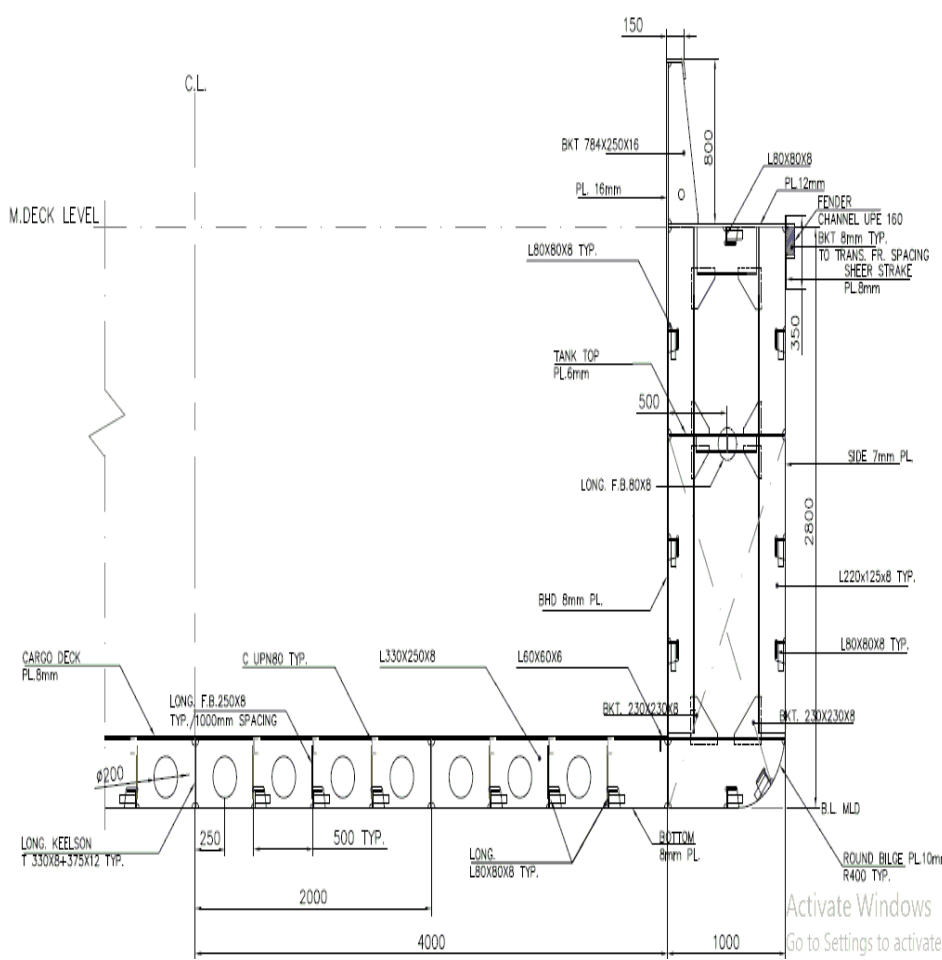

Fig. 9 Structural scantlings at the midship section

\subsection{Primary hull girder analysis}

In this section, the primary hull girder analysis on the basis of the design rules and a MAXSURF Software is calculated for the case study.

1. The still water bending moment is calculated according to $\mathrm{BV}$ rules of the barge is as follows [7].

$$
\mathrm{M}_{\mathrm{S}}=0.273 \mathrm{~L}^{2} \mathrm{~B}^{1.34} \mathrm{D}^{0.15}\left(1-\mathrm{C}_{\mathrm{B}}\right) \quad \mathrm{kN} . \mathrm{m}
$$

The still water bending moment is $=22302.9 \mathrm{kN} . \mathrm{m}$

2. The still water bending moment by using MAXSURF software is calculated as follows.

Here, the still bending moment is calculated according to three different loading conditions for the barge. The highest value of the still water bending moment will be in the fully loaded condition.

$$
\mathrm{M}_{\mathrm{st}}=6155.368 \mathrm{kN}
$$

It is noticed that the acting still water moment of the barge is $(6155.368 \mathrm{kN})$, which is less than that calculated by rules $(22302.9$ kN.m)

The distribution of the of still bending moment is shown in Fig. 10

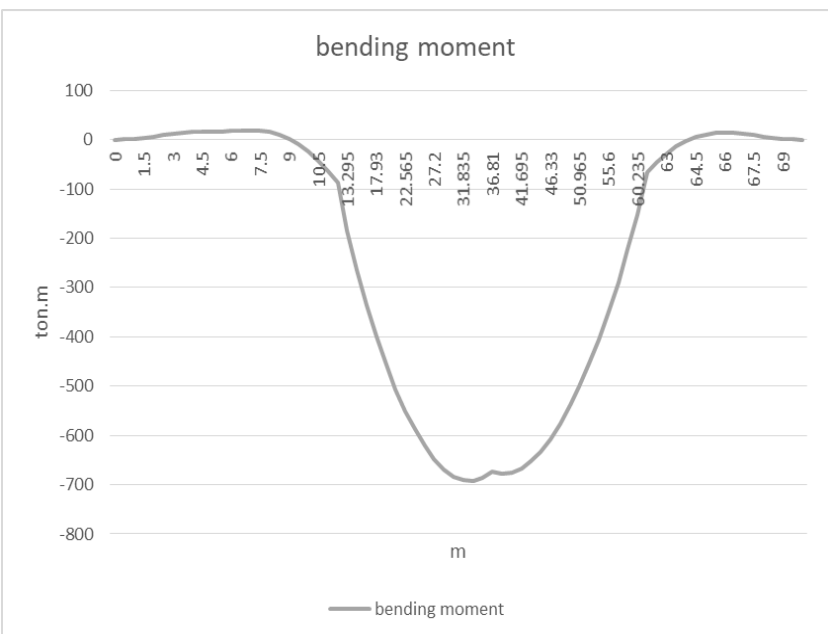

Fig. 10 Bending moment for the fully loaded condition

3. Calculation of section modulus for the midship section of the unit.

$$
\mathrm{Z}_{\mathrm{B}}=\frac{\text { TNA }}{\mathrm{YR}}
$$

$\mathrm{Z}_{\mathrm{B}=3.79 \mathrm{~m}^{3}}$

$$
\mathrm{Z}_{\mathrm{D}}=\frac{r N A}{\mathrm{YN}}
$$

$\mathrm{Z}_{\mathrm{D}}=1.46 \mathrm{~m}^{3}$

Compounding of stresses at bottom plate as mentioned before $=165.73 \mathrm{MPa}$ 


\section{Modification of the barge structure}

As mentioned before, there are no waves in the River Nile and wave bending moment does not exist. There is also a large difference in the values of the still water bending moment as given from the empirical formula from the rules and the actual bending moment calculated by MAXSURF software. In this study, an attempt is made to reduce scantlings of the barge using basic structure methods to save steel weight and assure that the structure is completely safe, as shown in the flow chart. (See Fig.11)

Some constraints are associated with reducing scantlings of the structure such as:

- The acting stress that affects the structure should be less than the yield stress of the material and the Euler buckling stress.

- The thickness of the plates used in the structure shouldn't be less than $6 \mathrm{~mm}$.

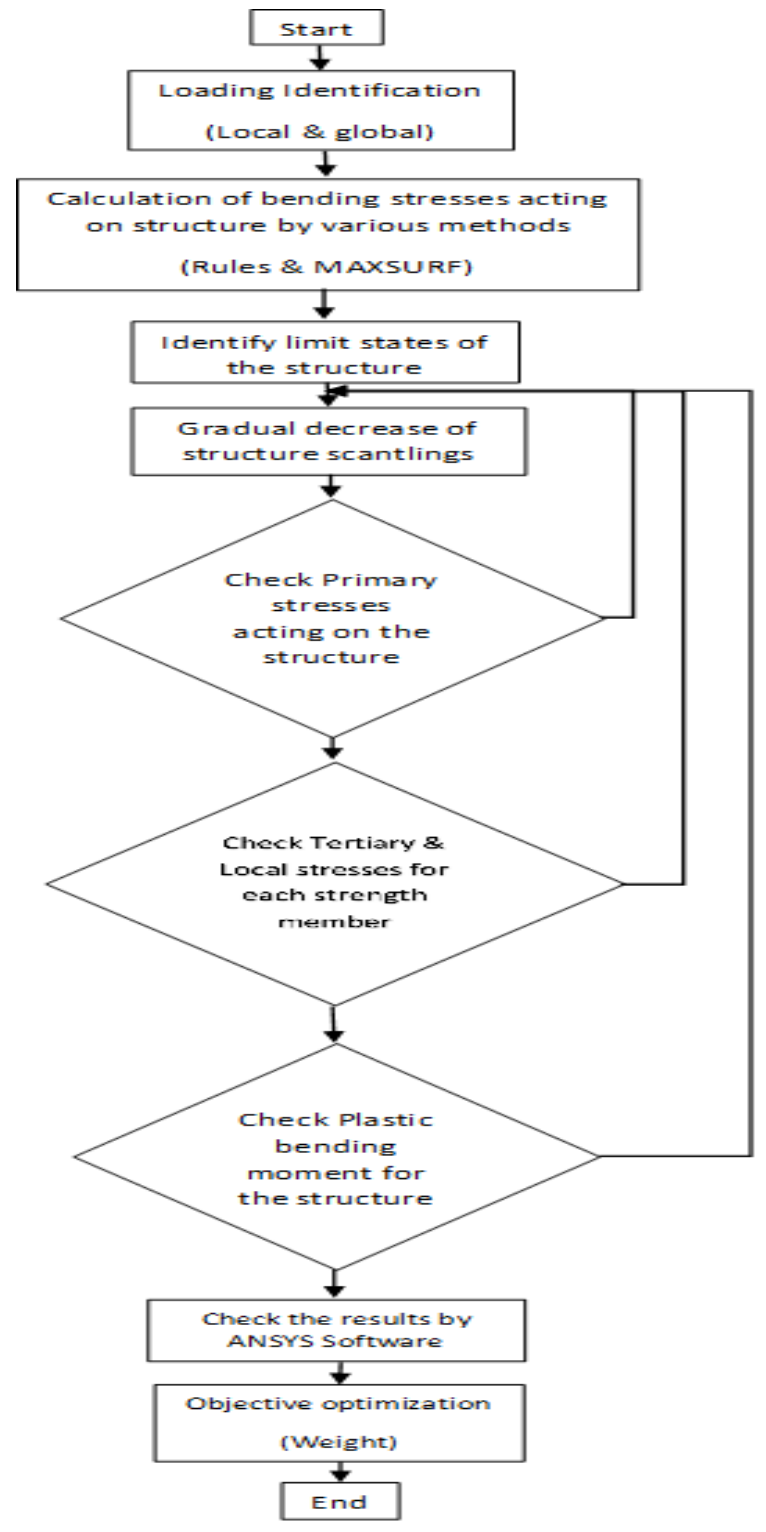

Fig. 11 Modification Flow chart
It is to be noted that the acting bending moment on the structure due to still water, cargo and various loads will produce tensile and compressive stresses on structure members.

- Tensile stresses will cause yielding of strength members. These stresses are less than yield stress of the material.

- Compressive stress will cause buckling of strength members. These stresses are less than Euler buckling stress.

\subsection{Procedure of modification of the midship} section

The scantlings of the barge are modified as follows:

- Decrease gradually the structural member scantlings step by step.

- Check primary stresses, tertiary and local stresses.

- If they are acceptable, repeat the first step again and check the stresses, till the scantlings reach the value $6 \mathrm{~mm}$.

The following table shows the scantlings of various structural member of the barge before and after modification:

Table 1: Scantlings of the barge before and after modifications

\begin{tabular}{|c|c|c|c|}
\hline $\begin{array}{c}\text { Structural } \\
\text { member }\end{array}$ & $\begin{array}{c}\text { Before } \\
\text { modification }\end{array}$ & $\begin{array}{c}\text { After } \\
\text { modification }\end{array}$ & $\begin{array}{c}\text { Reduction } \\
\text { in } \\
\text { thickness }\end{array}$ \\
\hline Bottom plate & $8 \mathrm{~mm}$ & $6 \mathrm{~mm}$ & $2 \mathrm{~mm}$ \\
\hline $\begin{array}{c}\text { Tank top } \\
\text { plate }\end{array}$ & $8 \mathrm{~mm}$ & $6 \mathrm{~mm}$ & $2 \mathrm{~mm}$ \\
\hline $\begin{array}{c}\text { Bottom } \\
\text { longitudinal }\end{array}$ & $80 * 80 * 8 \mathrm{~mm}$ & $\begin{array}{c}80 * 40 * 6 \\
\mathrm{~mm}\end{array}$ & $2 \mathrm{~mm}$ \\
\hline $\begin{array}{c}\text { Tank top } \\
\text { longitudinal }\end{array}$ & $80 * 80 * 8 \mathrm{~mm}$ & $80 * 40 * 6$ \\
$\mathrm{~mm}$ & $2 \mathrm{~mm}$ \\
\hline $\begin{array}{c}\text { Inner side } \\
\text { plate }\end{array}$ & $8 \mathrm{~mm}$ & $6 \mathrm{~mm}$ & $2 \mathrm{~mm}$ \\
\hline $\begin{array}{c}\text { Outer side } \\
\text { plate }\end{array}$ & $7 \mathrm{~mm}$ & $6 \mathrm{~mm}$ & $1 \mathrm{~mm}$ \\
\hline $\begin{array}{c}\text { Side } \\
\text { longitudinal }\end{array}$ & $80 * 80 * 8 \mathrm{~mm}$ & $80 * 40 * 6$ & $2 \mathrm{~mm}$ \\
\hline Bilge plate & $10 \mathrm{~mm}$ & $10 \mathrm{~mm}$ & 0 \\
\hline Sheer strake & $8 \mathrm{~mm}$ & $8 \mathrm{~mm}$ & 0 \\
\hline Deck plate & $12 \mathrm{~mm}$ & $8 \mathrm{~mm}$ & $4 \mathrm{~mm}$ \\
\hline $\begin{array}{c}\text { Weight per } \\
\text { unit length }\end{array}$ & $44.8 \mathrm{t} / \mathrm{m}$ & $43.6 \mathrm{t} / \mathrm{m}$ & $1.2 \mathrm{t} / \mathrm{m}$ \\
\hline
\end{tabular}

7.2. Calculation of elastic section modulus of the midship section for the unit after modification

$$
\begin{aligned}
& \mathrm{Z}_{\mathrm{B}}=3.64 \mathrm{~m}^{3} \\
& \mathrm{Z}_{\mathrm{D}}=1.35 \mathrm{~m}^{3}
\end{aligned}
$$

Compounding of stresses at bottom plate after modification $=182.56 \mathrm{MPA}$ 
7.3. The plastic section modulus of the mid ship section for the unit is given by:

$$
\begin{aligned}
\mathrm{Z}_{\mathrm{P}} & =10.31 \mathrm{~m}^{3} \\
\mathrm{M}_{\mathrm{P}} & =2577500 \mathrm{KN} . \mathrm{m}
\end{aligned}
$$

Here, the plastic moment that required to spread plasticity in the whole section of the inland water unit is $(2577500 \mathrm{KN} . \mathrm{m})$. This a greatest value of plastic moment can never reached, because the still water bending moment that can affect the unit in the River Nile is very limited, it is about (6155.368 KN.m).

\section{Validation of structural analysis}

In this section we check the tertiary stresses for particulars members by finite element model using ANSYS software such as:

\subsection{Center girder}
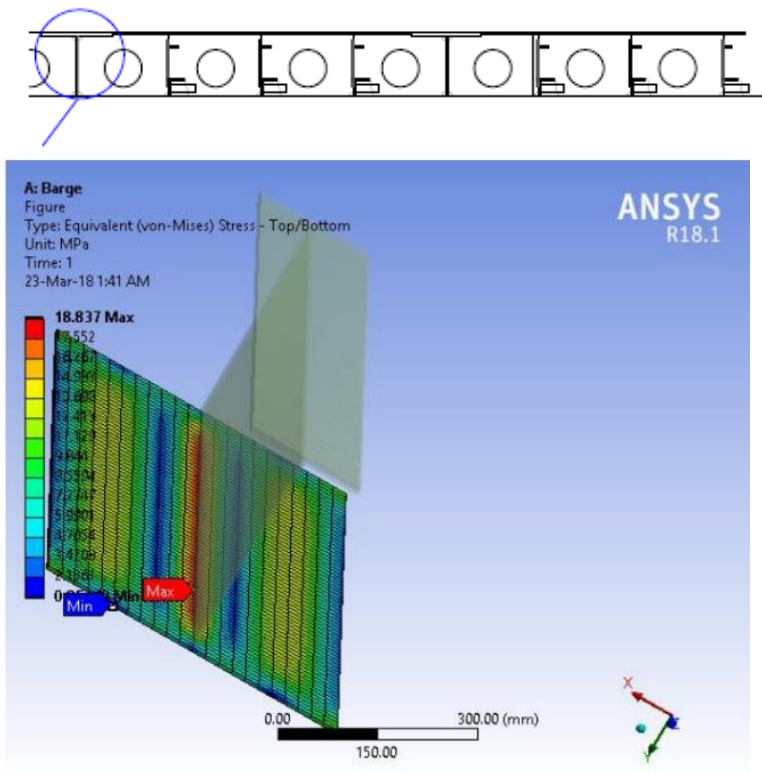

Fig.12-a Equivalent (von Mises) stress

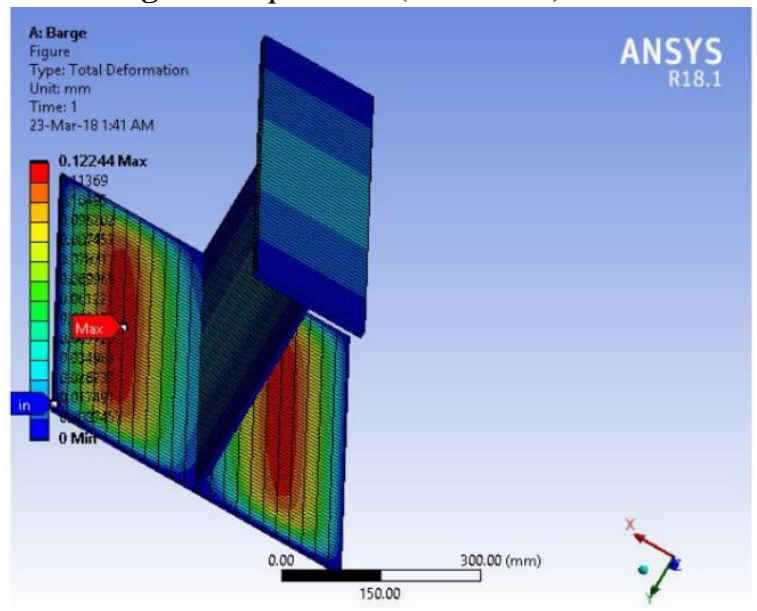

Fig.12-b Deflection contour at center girder

\subsection{Bottom plating}

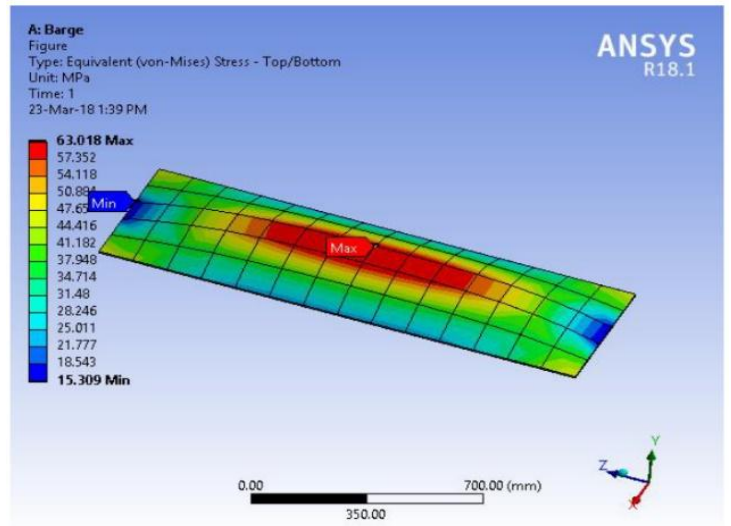

Fig.13-a Equivalent (von Mises) stress

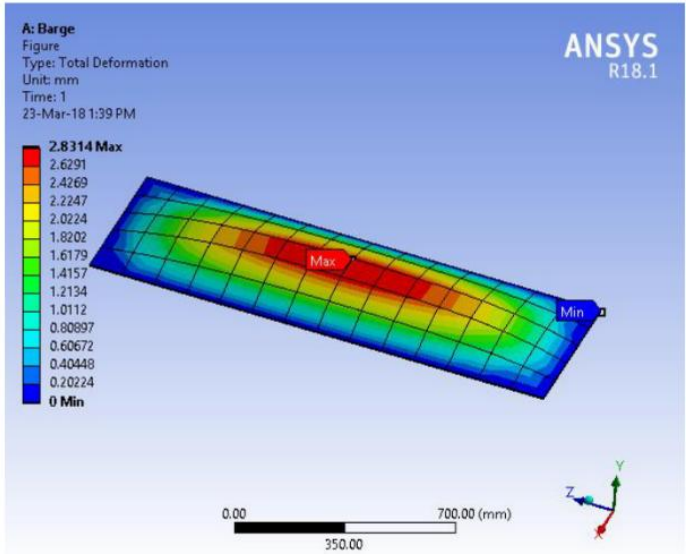

Fig.13-b Deflection contour at bottom plate

\subsection{Bottom plating and longitudinals}
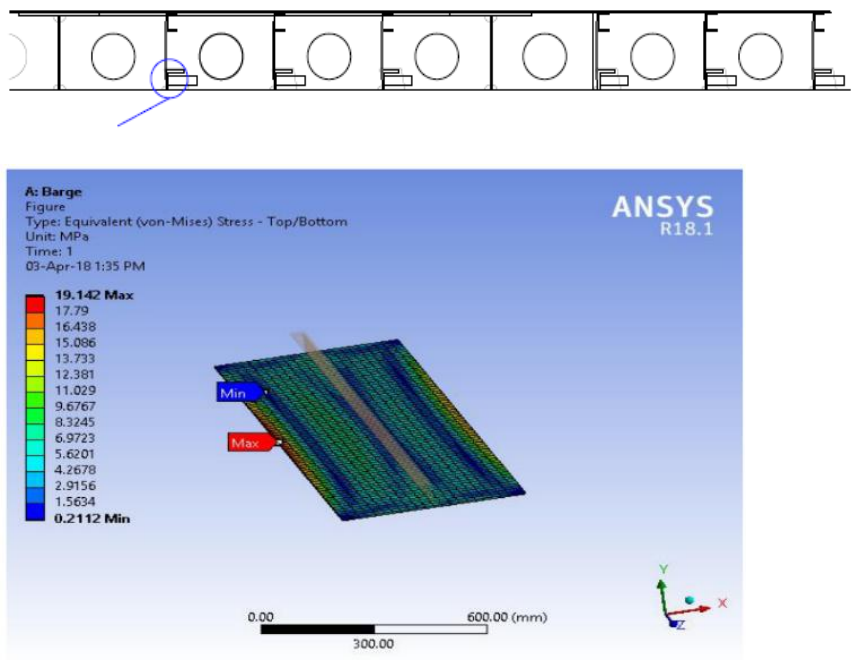

Fig.14-a Equivalent (von Mises) stress 


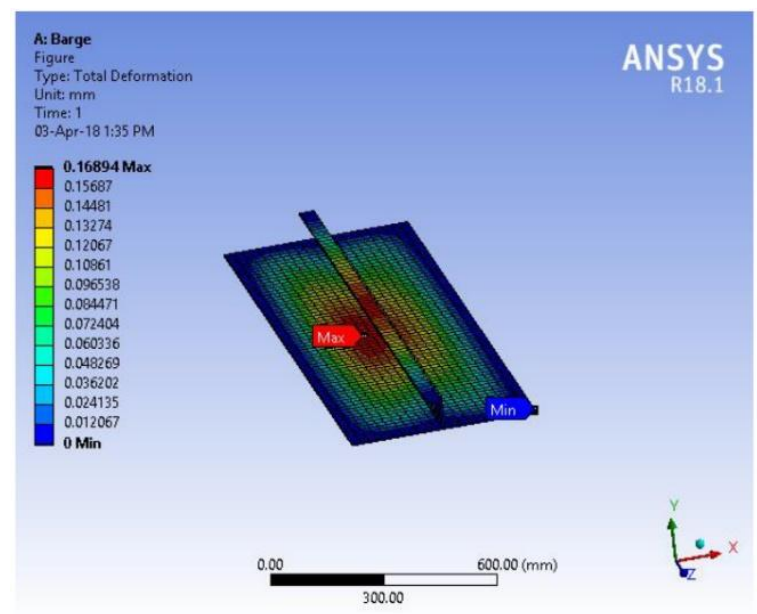

Fig.14-b Deflection contour at bottom plate and longitudinal

\subsection{Tank top plating and longitudinals}
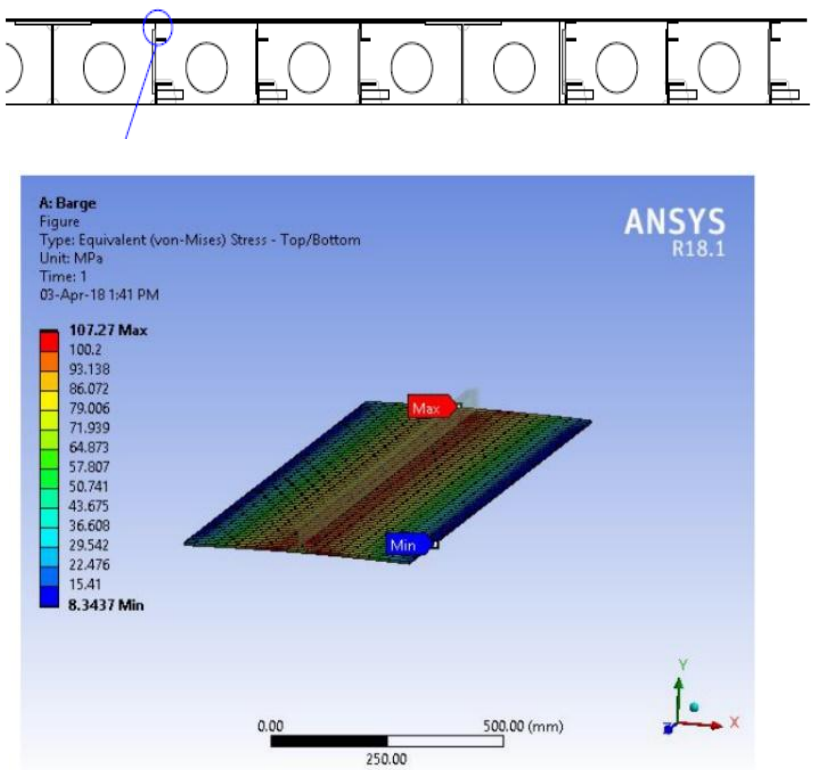

Fig.15-a Equivalent (von Mises) stress

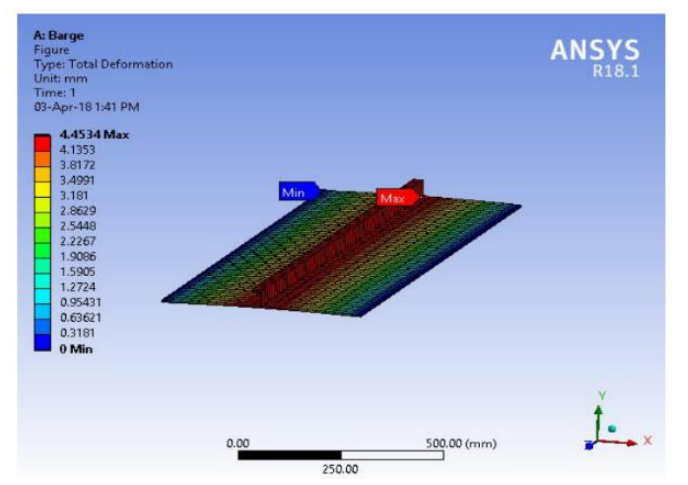

Fig.15-b Deflection contour at tank top plate and longitudinal

\section{Comparison between stresses induced in various ship structural members}

The following table shows a comparison between the stresses induced in the barge by both methods (basic design and ANSYS software) when calculate tertiary stresses.

Table 2: Stresses induced in various structural members

\begin{tabular}{|c|c|c|c|}
\hline \multicolumn{4}{|c|}{ Comparison between stresses induced in variouls ship structural members } \\
\hline Type of stresses & $\begin{array}{l}\text { Ship structural } \\
\text { members }\end{array}$ & $\begin{array}{c}\text { Basic design } \\
\text { method }\end{array}$ & $\begin{array}{l}\text { ANSYS } \\
\text { Software }\end{array}$ \\
\hline Local stress & Bottom plate & 172.46 VPA & 63.01 MPA \\
\hline Tertiary stress & $\begin{array}{c}\text { Bottom } \\
\text { longitudinals }\end{array}$ & $21.378 \mathrm{MPA}$ & 19.142 MPA \\
\hline Tertiary stress & $\begin{array}{c}\text { tank top } \\
\text { longitudinals }\end{array}$ & 49.37 MPA & $35.262 \mathrm{MPA}$ \\
\hline Tertiary stress & Center girder & 9.672 MPA & 18.837 MPA \\
\hline
\end{tabular}

A deviation is between the basic design stresses and that developed by ANSYS software. This is due to the effect of boundary conditions and the idealized acting loads.

\section{Calculation of weight of the modified structure}

- The weight of the steel used in the building of this unit in the parallel middle body before modification $=44.8 \mathrm{t} / \mathrm{m}$.

- By applying the rational structural analysis, the decrease in steel weight for the case study in the parallel middle body is $=43.6 \mathrm{t} / \mathrm{m}$.

- That means that the weight saving of steel is $1.2 \mathrm{t} / \mathrm{m}$ after modification for parallel middle body.

- For bow and stern of the unit, the weight saving assumed is $0.6 \mathrm{t} / \mathrm{m}$.

- The amount of weight saving of steel used in this unit will be $77.4 \mathrm{t}$.

\section{CONCLUSION}

The main conclusions drawn up from this research work are:

- The still water bending moment calculated by rules is greater by $50 \%$ than the actual still water moment. 
- The existing inland water units designed according to classification society rules are overdesigned.

- Applying the developed rational structural design procedure will lead to saving in steel weight of ship hull girder without violating structural safety of the unit.

- Accordingly, a reduction of the initial cost of building Nile barges and increasing the cargo carrying capacity of the barges is achieved.

\section{References}

[1] Golam Zakaria, Sohanur Rahman , "Energy Efficiency Design Index (EEDI) for Inland Vessels in Bangladesh", Procedia Engineering, Volume 194, 2017, Pages 362369

[2] Tomasz Tabaczek, "Computation of flow around inland waterway vessel in shallow water”, Engineering, Volume 2008, Pages 97105

[3] Cezary Gołębiowsk, "Inland Water Transport in Poland", Transportation Research Procedia Volume 14, 2016, Pages 223-232

[4] Yasuhisa Okumoto, Yu Takeda, Masaki Mano , Tetsuo Okada , "Design of Ship Hull Structures: A Practical Guide for Engineers" 2009th Edition, springer, ISBN-13: 9783540884446

[5] Mohamed Shama, 2013th Edition, "Buckling of Ship Structures" springer, ISBN-13: 9783642179600

[6] You-Sheng Wu ,Wei-cheng Cui, Guo-jun Zhou, 2011 volume I "Practical Design of Ships and Other Floating Structures", Elsevier Science, ISBN-13: 978-0444539212

[7] BV Rules for inland water vessels 2017

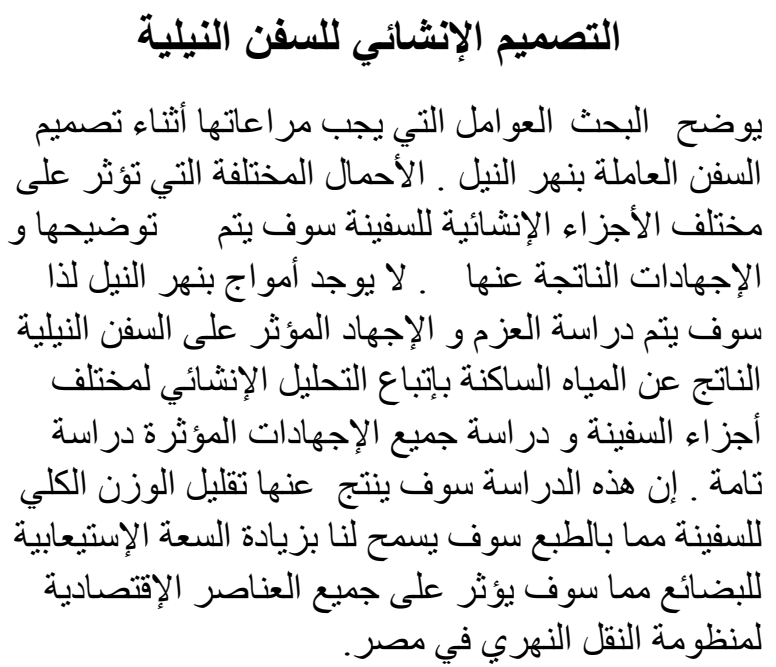

